\title{
Spread Bancário: \\ Uma Análise Comparativa a partir da Literatura Internacional*
}

\author{
Banking Spread: \\ A Comparative Analysis of the International Literature
}

Rodrigo Mendes Leal** Luiz Fernando de Paula***

Resumo: O objetivo deste artigo é avaliar a literatura empírica internacional sobre o spread bancário, considerando as especificidades da abordagem metodológica e dos tipos de medida adotada. Por meio da classificação e da análise comparativa da literatura, constata-se que, entre as características dos países, aquelas com maior destaque como determinantes do spread bancário são os fatores macroeconômicos e o grau de concentração de mercado. Ademais, identificaram-se, nos resultados, de acordo com a medida do spread utilizada, evidências de diferenciação que suscitaram a proposição de investigações sobre algumas questões relacionadas à temática tratada.

Palavras-chave: Instituições financeiras. Bancos. Spread bancário.

Abstract: This paper aims at evaluating the international empirical literature about banking spread, considering the characteristics of methodological approach and of the measure pattern of banking spread. The classification and comparative analysis of the literature suggests that the countries characteristics that are determinants of banking spread are mainly related to macroeconomic variables and market concentration degree. Furthermore, the paper show evidences about differences related to the empirical findings according the measure pattern, what suggests some propositions for future studies.

Keywords: Financial institutions. Banks. Banking spread.

JEL Classification: G2; G21; G14.

\footnotetext{
* Os autores agradecem os comentários de Ana Cláudia Loureiro, Antonio José Alves Junior e Gervasio Castro de Rezende, e de um parecerista anônimo, isentando-os, como de praxe, de qualquer responsabilidade pelo conteúdo final do artigo.

* * Economista do Banco Nacional do Desenvolvimento (BNDES) e doutorando do Programa de Políticas Públicas, Estratégia e Desenvolvimento da Universidade Federal do Rio de Janeiro (UFRJ). E-mail: rmendesleal@gmail.com

*** Doutor em Economia pela Universidade Estadual de Campinas (Unicamp). Professor da Faculdade de Ciências Econômicas (FCE) da Universidade do Estado do Rio de Janeiro (UERJ). Pesquisador do CNPq. E-mail: luizfpaula@terra.com.br
} 


\section{Introdução}

O spread bancário é uma medida do custo de intermediação financeira utilizada internacionalmente como indicador de sua eficiência (WORLD BANK; IMF, 2005).

Essa medida é definida de forma geral como a diferença entre os valores que o banco cobra dos tomadores de empréstimo e os valores que o banco remunera os depositantes (BROCK; ROJAS-SUAREZ, 2000). A utilização dessa definição abrangente tem como objetivo possibilitar uma ampla análise do que o spread bancário representa e de suas diferentes medidas na literatura empírica.

Sobre a interpretação do spread bancário, cabe destacar que maior spread bancário não implica necessariamente maior lucro, pois o lucro é o que sobra do spread bancário após a subtração dos custos da operação bancária, quais sejam: despesas administrativas, tributárias e de inadimplência (COSTA; NAKANE, 2005).

Considerando que a literatura empírica sobre spread bancário apresenta focos analíticos diferenciados, Dick (1999) propõe uma tipologia considerando três abordagens metodológicas dos estudos: evolução, estrutura e determinantes. A primeira abordagem - evolução - compreende a análise do comportamento dessa variável ao longo do tempo. A segunda abordagem, a da estrutura, constitui a análise dos componentes de destino (despesas ou resultado líquido) que o banco direciona o spread bancário. A partir da identidade contábil de composição do lucro, os modelos de decomposição normalmente consideram como componentes do spread bancário as despesas operacionais, as despesas de provisão para inadimplência, os impostos, o lucro e, com sinal contrário, as receitas líquidas de serviços. A abordagem dos determinantes, por sua vez, analisa em que medida a variação dos fatores explicativos do spread afeta seu comportamento, normalmente por meio de estimativas econométricas.

Além da importância da abordagem metodológica, Leal (2007) aponta que as especificidades de medida do spread bancário podem influenciar os resultados, e propõe uma tipologia que considera três categorias da medida, referentes a: origem da informação, abrangência da amostra e tipo de conteúdo. Em primeiro lugar vem a origem da informação, aspecto de maior destaque, pois o spread bancário pode ser calculado por meio de informações ex-ante, de acordo com as taxas (preços) estabelecidas pelos bancos, ou informações ex-post, de acordo com o resultado (contábil) efetivamente realizado dos bancos (DEMIRGUÇ-KUNT; HUIZINGA, 1999). Em segundo lugar, é importante identificar a abrangência da amostra de bancos, tendo em vista que o indicador geral consiste na agregação de informações de diversas modalidades de crédito e diversos bancos (NAKANE; COSTA, 2005). Em terceiro lugar, quanto ao conteúdo da medida, deve ser observada a definição das taxas de receita e de despesa de intermediação financeira, que podem considerar ou não as tarifas e comissões cobradas 
pelos bancos aos depositantes e tomadores de empréstimos (BROCK; ROJASSUAREZ, 2000).

O Brasil apresenta elevados spreads bancários em relação aos padrões mundiais ${ }^{1}$, que contribuem para a combinação desfavorável de baixa relação crédito/PIB e de altas taxas de juros das operações de crédito no país, constituindo restrição à obtenção de crédito e, por consequência, ao crescimento econômico do país. No país, o spread bancário é objeto de extensa e diversificada literatura, tendo sido realizada por Leal (2007) uma análise comparativa dos estudos empíricos sobre sua estrutura e determinantes.

Nesse contexto, o objetivo deste artigo é avaliar a literatura empírica internacional sobre o spread bancário, com o intuito principal de contribuir para o diagnóstico dos seus determinantes e da sua estrutura, considerando as especificidades dos tipos de medida do spread bancário.

Uma etapa prévia da investigação foi a busca de literatura empírica internacional sobre o spread bancário ${ }^{2}$, até o segundo semestre de 2006 . Em seguida, foi realizada a classificação dos estudos, de acordo com a tipologia adotada por Leal (2007), no que se refere à abordagem analítica (evolução, estrutura e determinantes) e tipo da informação da medida do spread (ex-ante ou ex-post). A análise é apresentada em duas etapas, a primeira para análises individualizadas por país (seção 2) e a segunda para análise de um conjunto de países (seção 3), considerando as diferenças metodológicas e do escopo de análise desses dois grupos. Por fim, são apresentadas as considerações finais (seção 4).

\section{Literatura Empírica Estrangeira com Análise do Spread Bancário por País}

\subsection{A Literatura Empírica Estrangeira com Análise Individualizada por País}

O Quadro 1 contém o levantamento bibliográfico de estudos que realizam análise individualizada por país, classificados em relação à abordagem e tipo do spread. Dentre eles, observa-se que Dick (1999) e Brock e Rojas-Suarez (2000) comparam diversos países, mas como a metodologia do estudo é de análise individualizada por país, esses estudos são considerados nesta seção.

A partir da avaliação prévia e classificação, realiza-se a revisão da literatura selecionada, com foco na metodologia e nos resultados encontrados. Destacamse, a princípio, as inovações metodológicas de cada um dos cinco estudos: Ho

Há evidências de que o spread bancário médio (ex-ante) do Brasil ao longo da década de 1990 foi superior a 50\%, enquanto a média na América Latina esteve entre $10 \%$ e $15 \%$ a.a. em todo o período 1993-2002 (SINGH et al., 2005). Na mesma direção, Paula e Leal (2006) mostram que o Brasil apresenta elevados spreads bancários e taxas de empréstimos, em relação aos padrões internacionais. Entendemos por literatura internacional, neste artigo, estudos empíricos sobre spread bancário que são referenciados a experiência de outros países (i.e., não incluindo o Brasil). É interessante notar que isso não prejudica a utilização de estudos sobre spread bancário na América Latina, já que esses em geral (exceção de GELOS, 2006) não incluem o Brasil, possivelmente por ser um outlier em função de seus elevadíssimos spreads. A exceção é o estudo de Afanasieff et al. (2002), que utiliza o modelo de dois estágios de Ho e Saunders (1981). 
e Saunders (1981) propõem um modelo teórico e o estimam empiricamente; Barajas, Steiner e Salazar (1999) analisam a evolução do spread ex-ante e expost; Dick (1999) analisa a evolução e a estrutura do spread ex-ante e ex-post; Brock e Rojas-Suarez (2000) utilizam diferentes medidas do spread ex-post; e Brock e Franken (2003) analisam comparativamente a evolução e determinantes do spread ex-ante e ex-post.

\begin{tabular}{|c|c|c|c|}
\hline Estudo & País & Periodo & $\begin{array}{c}\text { Abordagem e } \\
\text { tipo do spread }\end{array}$ \\
\hline $\begin{array}{c}\text { Ho e Saunders } \\
\text { (1981) }\end{array}$ & Estados Unidos & $1976-1979$ & $\begin{array}{c}\text { Determinantes do } \\
\text { spread ex-post. }\end{array}$ \\
\hline $\begin{array}{c}\text { Barajas, Steiner e } \\
\text { Salazar (1999) }\end{array}$ & Colômbia & $1974-1996$ & $\begin{array}{c}\text { Evolução do } \\
\text { spread ex-ante e } \\
\text { ex-post. Estrutura } \\
\text { e determinantes } \\
\text { do spread ex-post. }\end{array}$ \\
\hline $\begin{array}{c}\text { Dick (1999) } \\
\text { Costa Rica, } \\
\text { El Salvador, } \\
\text { Honduras e } \\
\text { Nicarágua }\end{array}$ & $1990-1998$ & $\begin{array}{c}\text { Evolução e } \\
\text { estrutura do } \\
\text { spread ex- } \\
\text { ante e ex-post. } \\
\text { Determinantes do } \\
\text { spread ex-post. }\end{array}$ \\
\hline $\begin{array}{c}\text { Brock e Rojas- } \\
\text { Suarez (2000) }\end{array}$ & $\begin{array}{c}\text { Argentina, Bolívia, } \\
\text { Chile, Colômbia, } \\
\text { México e Peru }\end{array}$ & $1991-1996$ & $\begin{array}{c}\text { Evolução e } \\
\text { determinantes do } \\
\text { spread ex-post. }\end{array}$ \\
\hline $\begin{array}{c}\text { Afanasieff, Lhacer } \\
\text { e Nakane (2002) }\end{array}$ & Brasil & $1997-2002$ & $\begin{array}{c}\text { Evolução e } \\
\text { determinantes do } \\
\text { spread ex-ante. }\end{array}$ \\
\hline $\begin{array}{c}\text { Brock e Franken } \\
\text { (2003) }\end{array}$ & Chile & $\begin{array}{c}\text { Evolução e } \\
\text { determinantes do } \\
\text { spread ex-ante e } \\
\text { ex-post. }\end{array}$ \\
\hline
\end{tabular}

Quadro 1 - Literatura empírica internacional com análise do spread bancário por país

Fonte: Elaborado pelos autores com base na literatura citada.

Ho e Saunders (1981) desenvolveram um modelo de determinação do spread bancário que integra as hipóteses de hedge (equilíbrio da maturidade do ativo e passivo) e da teoria microeconômica da firma bancária (maximização da utilidade esperada do lucro), considerando o banco como negociador avesso ao risco, abstraindo o risco do crédito e assumindo que todos os depósitos e 
empréstimos são processados sem custo. Essa parcela da margem explicada pela incerteza na transação é denominada "spread puro". O modelo de decisão de um período tem como hipótese que o banco maximiza a utilidade esperada de sua riqueza final, fixando os preços dos empréstimos e dos depósitos no início do período, enquanto as quantidades de empréstimos e depósitos são determinadas de modo exógeno.

A partir dessas condições de contorno, os autores demonstram teoricamente que os bancos sempre irão demandar uma margem positiva, mesmo em mercados altamente competitivos, devido à incerteza na intermediação financeira, que acarreta a possibilidade de descasamento dos fluxos estocásticos de empréstimos e depósitos, e sugerem que as estruturas do ativo e passivo devem ser analisadas em conjunto. Além disso, são definidos como determinantes do "spread puro": i) aversão ao risco; ii) estrutura de mercado; iii) tamanho das transações; e iv) risco das taxas de juros.

O modelo dos determinantes do spread é estimado a partir de dados contábeis de uma amostra de 53 bancos dos Estados Unidos, entre o último trimestre de 1976 e o último trimestre de 1979, por meio de regressão em dois estágios. No primeiro estágio, estima-se o "spread puro" para cada período por intermédio do coeficiente linear da regressão em cross-section da margem de intermediação, controlando três fatores específicos aos bancos, todos com expectativa de coeficiente positivo: i) risco de inadimplência; ii) custo de oportunidade das reservas requeridas; e iii) pagamentos implícitos de juros nos depósitos. No segundo estágio, testa-se o modelo de determinação do "spread puro" por meio de regressão em série temporal, examinando a relação dos "spreads puros" estimados com a variável risco de juros (variância da taxa de juros de títulos do governo).

Os resultados indicam que, entre os determinantes da margem de intermediação considerados, apenas o coeficiente dos pagamentos implícitos de juros nos depósitos e o coeficiente linear, interpretado como o spread puro, são significativos, ambos positivos, de acordo com a expectativa dos autores. No segundo estágio, a regressão dos determinantes do spread puro indicou significância para o coeficiente linear positivo, interpretado como indicador da estrutura de mercado, nas estimativas para todas as maturidades de taxas de juros. $\mathrm{O}$ risco de juros, no entanto, se mostrou significativo e positivo apenas para a maturidade de juros de um ano. Ho e Saunders (1981) analisam também a amostra desagregada por tamanho de banco e observam que os grandes bancos apresentam spread puro sutilmente menor do que os pequenos, associando esse resultado às evidências, fracas, de diferença no indicador de estrutura de mercado para esses grupos. Registra-se a ressalva de que o coeficiente linear do segundo estágio possivelmente contém efeito de outros fatores não considerados pelo modelo, além da estrutura de mercado.

Barajas, Steiner e Salazar (1999) analisam o comportamento do spread bancário na Colômbia em dois períodos, de 1974 a 1988 e de 1991 a 1996, sendo que apenas no segundo período utilizam dados desagregados por banco. Em uma 
primeira etapa do estudo, os autores analisam a evolução do spread ex-post para o primeiro período e também analisam comparativamente a do spread ex-ante e do spread ex-post no segundo período, encontrando diferenças significativas no nível e no comportamento dessas duas medidas do spread. Além disso, os autores identificam que a variabilidade para o spread ex-post e para outros indicadores contábeis é mais significativa entre os bancos ao longo do tempo, no período 1991-1996. Assim sendo, analisam os indicadores em separado para bancos privados e públicos, encontrando diferenças significativas de nível e de comportamento e recomendando que as técnicas de análise considerem essa heterogeneidade. Ainda para o mesmo período, é analisada a correlação positiva entre o spread ex-post e a variável peso dos empréstimos em atraso, por meio do teste de causalidade de Granger, que resulta em indícios de que a direção de causalidade é da inadimplência para o spread.

$\mathrm{Na}$ segunda etapa do estudo, os autores analisam os determinantes do spread ex-post. No segundo período, de 1991 a 1996, quando os dados são disponíveis por banco, utilizam regressão em painel, em separado para os bancos públicos e para os privados, encontrando heterogeneidade significativa entre os bancos.

$\mathrm{Na}$ terceira etapa do estudo, os autores analisam a estrutura do spread exante para o sistema bancário e para o subconjunto público e privado, por meio da decomposição do spread estimado na regressão econométrica da segunda etapa do estudo entre as variáveis explicativas da regressão, de acordo com os coeficientes estimados. Em geral, Barajas, Steiner e Salazar (1999) sugerem que ocorreu na Colômbia, na década de 1990, a redução da importância do componente poder de mercado e o aumento da importância da qualidade de empréstimos e do custo operacional.

Dick (1999) analisa o spread bancário, entre 1990 e 1998, em cinco países da América Central - Costa Rica, El Salvador, Guatemala, Honduras e Nicarágua -, delimitando a análise do spread bancário em três abordagens: evolução, estrutura e determinantes. Na terceira abordagem, o autor analisa os determinantes do comportamento do spread ex-post, estimando para cada país uma regressão em painel. Considera que, para analisar os determinantes das decisões de preço do banco, seria mais adequado utilizar o spread exante, mas justifica sua não utilização no modelo econométrico pela limitação de disponibilidade e de qualidade dos dados, devido à quantidade e heterogeneidade das operações de crédito.

Em geral, para todos os países analisados, os resultados obtidos indicam que os custos operacionais são os mais importantes componentes da estrutura do spread bancário, seguidos pelo custo de requerimento de reserva. Os resultados do modelo econométrico dos determinantes, por sua vez, indicam uma relação significativamente positiva entre os custos operacionais e o spread bancário para todos os países analisados. Além disso, os custos de 
requerimento de reserva e a inadimplência apresentaram ambigüidade nos resultados. Os custos de requerimento de reserva apresentaram coeficiente significativo e positivo para El Salvador e Honduras, e significativo e negativo para Costa Rica. A inadimplência apresentou coeficiente significativo para Guatemala e Nicarágua, sendo para o primeiro país negativo e para o segundo positivo.

Como conclusão, Dick (1999) sugere que o grau de poder de mercado parece não ser um importante determinante do spread bancário, exceto para a Costa Rica; e que as reformas caracterizadas pelo incentivo de novos entrantes devem continuar, com a finalidade de aumentar o grau de competição e forçar a diminuição das despesas operacionais dos bancos.

Brock e Rojas-Suarez (2000) analisam diferentes medidas do spread ex-post e seu comportamento para Argentina, Bolívia, Chile, Colômbia, México e Peru, com dados contábeis de uma amostra de bancos entre o primeiro trimestre de 1991 e o último trimestre de 1996. O escopo dos autores é investigar o motivo da não redução do spread bancário nesses países da América Latina, num período de aprofundamento financeiro resultante da reforma do setor, caracterizada pela redução dos requerimentos de reservas e das restrições diretas ao crédito e às taxas de juros.

Em primeiro lugar, Brock e Rojas-Suarez (2000) analisam a evolução de seis medidas de spread ex-post, encontrando diferenças de nível significativas entre as medidas do spread em todos os países. Além disso, os autores observam que, para a mesma medida de spread, a dispersão entre os bancos é significativa em todos os países, e alertam que "pode ser enganoso o foco em agregados para entender o comportamento do spread" (BROCK; ROJAS-SUAREZ, 2000, p. 127). Um exemplo da limitação da análise de indicadores agregados do spread é considerado na análise de diferenças de custos, que podem refletir diferenças nos tipos de produtos oferecidos pelos diferentes bancos, ou então as diferenças entre os bancos públicos e privados. Em segundo lugar, os autores utilizam o modelo de Ho e Saunders (1981) com regressão em painel de dois estágios, com dados por banco, para estimar os determinantes do spread para cada um dos países individualmente, exceto o México.

Os resultados do primeiro estágio indicam que alguns dos países apresentam relação positiva e significativa com o spread as seguintes variáveis: relação capital-ativo (Bolívia e Colômbia), custo (Argentina e Bolívia) e liquidez (Bolívia, Colômbia e Peru). Esses resultados confirmam, segundo os autores, os resultados encontrados em estudos para os países desenvolvidos (como em Saunders e Schumacher, 2000). Por outro lado, o risco de inadimplência não correspondeu à expectativa de relação positiva com o spread bancário (exceto para a Colômbia), motivada pelos resultados de estudos com países desenvolvidos (como em Angbazo, 1997). Os autores associam esse resultado à inadequada provisão para perdas nos empréstimos e às estratégias de crescimento de alto risco dos bancos. Cabe acrescentar às observações dos autores que Ho e Saunders (1981) não encontraram significância para a mesma medida de risco de inadimplência como 
determinante do spread ex-post nos Estados Unidos. Além disso, o indicador expost do spread bancário reflete o resultado realizado nos empréstimos, resultando que um banco com maior inadimplência pode apresentar menor margem de intermediação no mesmo período, simplesmente pelo fato de não ter antecipado a inadimplência em suas taxas ex-ante. A lógica é diferente no spread ex-ante ou em um modelo de comportamento do banco, como o de Ho e Saunders, em que ao se deparar com maior expectativa de risco de inadimplência, o banco tende a aumentar o spread ex-ante.

Quanto às variáveis macroeconômicas, no segundo estágio, Brock e Rojas-Suarez (2000) observam que, para a maioria dos países, a incerteza macroeconômica, representada pela volatilidade de juros (Bolívia e Chile) e pela inflação (Colômbia, Chile e Peru), apresenta relação positiva com o spread, corroborando os resultados de estudos para os países desenvolvidos (SAUNDERS; SCHUMACHER, 2000).

Concluindo, Brock e Rojas-Suarez (2000) sugerem, apesar da ressalva do risco da análise de agregados para a compreensão do spread bancário, que as regressões foram capazes de explicar os determinantes dos spreads bancários em três dos cinco países analisados, sendo que, para a Colômbia e Chile, os fatores microeconômicos e macroeconômicos foram relevantes, enquanto para a Bolívia, o spread bancário foi explicado predominantemente pelos fatores microeconômicos.

Afanasieff, Lhacer e Nakane (2002) analisam os determinantes do spread bancário no Brasil e identificam inicialmente dois fatos estilizados sobre o comportamento dos spreads após o Plano Real, a saber: (a) a queda pronunciada das taxas de juros após $1995 ;^{3}$ e (b) uma dispersão elevada e persistente entre as taxas de empréstimos praticadas pelos bancos. Esses fatos justificaram a utilização da metodologia primeiramente empregada por Ho e Saunders (1981) para a determinação dos spreads bancários. Em um primeiro passo, utilizou-se um painel de dados para 142 bancos comerciais entre fevereiro de 1997 e novembro de 2000, de forma a captar a influência individual (por banco) de variáveis microeconômicas ${ }^{4}$ sobre o spread, ou seja, aquelas relacionadas às características específicas dos bancos. A partir desse painel, foi possível obter uma estimativa do spread puro. Numa segunda etapa, estimou-se, através de um modelo estrutural, a influência de longo prazo de variáveis macroeconômicas (taxa de

3 O ambiente internacional mais estável, a queda na taxa de overnight e as medidas adotadas pelo Banco Central contribuíram para a redução dos spreads (PAULA; ALVES JR. 2003, p. 358). Em relação a essas últimas, devemos destacar a redução do compulsório sobre depósitos à vista, de $75 \%$ para $45 \%$, e dos depósitos à prazo de $20 \%$ para $0 \%$, novas regras para a provisionamento de créditos de liquidação. duvidosa, redução da alíquota do IOF de $6 \%$ para $1,5 \%$ e o desenvolvimento da central de risco de crédito.

As variáveis selecionadas por Afanasieff et al. (2002) foram: (a) número de agências bancárias; (b) razão entre os depósitos que não rendem juros e os ativos operacionais totais; (c) razão entre os ativos que rendem juros e os ativos totais; (d) custos operacionais; (e) liquidez do banco; (f) razão entre a receita de serviços e as receitas operacionais totais; (g) valor líquido do banco; e (h) alavancagem do banco. 
juros de mercado, uma medida de prêmio de risco: spread do C-bond sobre um título do Tesouro dos Estados Unidos com a mesma maturidade, taxa de inflação, taxa de crescimento do produto, depósito compulsório sobre depósitos a vista e taxa de imposto financeiro - i.e., IOF, PIS-COFINS e CPMF) sobre o spread puro calculado anteriormente.

Os resultados das regressões no primeiro estágio mostram que as seguintes variáveis apresentam significância estatística: razão entre os depósitos que não rendem juros e os ativos totais, custos operacionais, razão entre receita de serviços e receitas operacionais totais - tendo todas essas variáveis um efeito positivo sobre spread bancário -, além de uma dummy para os bancos estrangeiros, cujo resultado negativo indica que esses bancos cobram spreads menores em média. Considerando a pequena diferença entre o spread real e o spread puro. aquele resultante do primeiro estágio que isola os efeitos microeconômicos, bem como que os coeficientes estimados no segundo passo foram significativos, os resultados indicam a relevância dos aspectos. Os resultados da regressão sugerem que o spread tende a aumentar com a elevação da taxa básica de juros, do prêmio de risco, do crescimento do produto e dos impostos. Ao contrário do esperado, ${ }^{5}$ a taxa de inflação afetou negativamente o spread no período, possivelmente devido a fato de que inflação possa estar capturando o efeito da apropriação da senhoriagem do banco sobre o spread.

Brock e Franken (2003) analisam os determinantes do spread bancário no Chile no período 1994-2001, utilizando seis indicadores do spread. ${ }^{6}$ Os autores observam que, em geral, a dispersão entre os bancos é maior que no tempo, assim como encontrado em Brock e Rojas-Suarez (2000), o que pode levar a conclusões errôneas na interpretação das variáveis agregadas.

Os resultados da regressão em painel para os dois indicadores contábeis, ou ex-post, são similares, com relevância para a relação positiva do spread com a variável explicada defasada (o próprio spread no período anterior), pagamento implícito de juros, volatilidade macroeconômica (da taxa de câmbio e da taxa de juros), tamanho do banco e concentração do setor; e para a relação negativa com eficiência operacional e número de agências. Todavia, ao comparar os resultados do spread ex-post com os resultados dos indicadores ex-ante, é constatada diferença nos sinais dos coeficientes da concentração, volatilidade do câmbio e variáveis de ciclo de negócios.

Concluindo, Brock e Franken (2003) recomendam cuidado na interpretação das estimativas empíricas dos spreads, e propõem que seja combinada a análise de indicadores contábeis com a dos spreads ex-ante desagregados, com a finalidade de obter um retrato mais completo do comportamento dos bancos.

5 Silva, Oreiro e Paula. (2007) utilizam um modelo VAR com spread ex-ante, produto industrial, taxa de juros Selic, taxa de inflação e taxa de câmbio para o período 1994-2005, de modo que os principais determinantes macroeconômicos sejam a taxa de juros Selic e taxa de inflação, ambas com choques positivos.

6 Como indicadores do spread ex-post, a partir de dados contábeis, consideram a margem de intermediação e o spread médio (razão da receita de juros pelo ativo que rende juros menos a razão da despesa de juros pelo passivo que rende juros). Também utilizam quatro indicadores para o spread ex-ante, a partir da diferença da taxa de empréstimo pela taxa de captação, sendo o primeiro calculado com taxas de longo prazo em peso chileno e os outros três com diferentes taxas de curto prazo.

LEAL, R. M.; PAULA L. F. Spread bancário: uma análise comparativa... 


\subsection{Uma Avaliação da Literatura}

Após a análise da literatura empírica internacional com análise individualizada por país enumerada do Quadro 1, objetiva-se, nesta seção, extrair algumas conclusões da literatura. Em primeiro lugar, a análise propiciou a conclusão de que é necessário cuidado na interpretação das estimativas empíricas do spread, devido aos seguintes fatores:

i) as medidas do spread ex-ante e ex-post apresentaram diferenças em relação ao comportamento na Colômbia (BARAJAS; STEINER; SALAZAR., 1999) e aos determinantes no Chile (BROCK; FRANKEN, 2003), resultados que sugerem importância para a análise comparativa do spread dessas duas fontes de informação;

ii) as diferentes medidas de spread ex-post podem apresentar diferença significativa de nível, como no caso de seis países da América Latina (BROCK; ROJAS-SUAREZ, 2000), o que sugere importância na análise comparativa de diferentes especificações de medida do spread;

iii) os estudos constataram significativa heterogeneidade entre os bancos em diversos países da América Latina (BROCK; ROJAS-SUAREZ, 2000; BARAJAS; STEINER; SALAZAR, 1999). Brock e Rojas-Suarez (2000) registram que pode ser enganoso o foco em agregados para entender o comportamento do spread.

Em segundo lugar, é possível destacar, em geral, considerando as limitações das estimativas empíricas, as seguintes variáveis explicativas que apresentaram relação significativa e positiva com o spread nos países da América do Sul:

i) volatilidade macroeconômica, medida pela volatilidade da taxa de juros na Colômbia (BARAJAS; STEINER; SALAZAR, 1999), Bolívia e Chile (BROCK; ROJAS-SUAREZ, 2000), pelas elevadas taxas de juros no Brasil (AFANASIEFF; LHACER; NAKANE, 2002) e pela inflação na Colômbia, Chile e Peru (BROCK; ROJAS-SUAREZ, 2000)7, confirmando a hipótese do modelo de Ho e Saunders (1981);

ii) características microeconômicas, como o custo operacional para a Colômbia (BARAJAS; STEINER; SALAZAR, 1999), Argentina e Bolívia (BROCK; ROJAS-SUAREZ, 2000); relação capital-ativo para Bolívia e Colômbia e liquidez para Bolívia, Colômbia e Peru (BROCK; ROJASSUAREZ, 2000). 7 No caso do Brasil, como visto, Afanasieff, Lhacer e Nakane (2002) mostram uma relação negativa entre
spread e taxa de inflação. 
Em resumo, a evidência empírica sugere que os fatores microeconômicos têm sido o principal determinante do spread na Bolívia; que os fatores micro e macro impactaram os spreads no Chile e na Colômbia; e que os fatores macroeconômicos foram importantes na determinação do spread, no caso do Brasil. Ademais, no caso do spread na Argentina e no Peru, os fatores micro e macro não parecem explicar adequadamente sua evolução (BROCK; ROJASSUAREZ, 2000).

\section{Literatura Empírica Internacional com Análise do Spread Bancário por Grupo de Países}

3.1 A Literatura Empírica Internacional com Análise de um Conjunto de Países

O Quadro 2 enumera alguns principais estudos sobre spread bancário que têm como escopo a análise de um conjunto de países, que serão analisados com mais detalhes no decorrer desta seção.

\begin{tabular}{|c|c|c|c|}
\hline Estudo & $\begin{array}{c}\text { Número de } \\
\text { Países }\end{array}$ & Período & $\begin{array}{c}\text { Abordagem e } \\
\text { tipo do spread }\end{array}$ \\
\hline $\begin{array}{c}\text { Demirguç-Kunt e } \\
\text { Huizinga (1999) }\end{array}$ & 80 & $1988-1995$ & $\begin{array}{c}\text { Estrutura e } \\
\text { determinantes do } \\
\text { spread ex-post. }\end{array}$ \\
\hline $\begin{array}{c}\text { Saunders e } \\
\text { Schumacher } \\
\text { (2000) }\end{array}$ & 7 (OCDE) & $1988-1995$ & $\begin{array}{c}\text { Evolução e } \\
\text { determinantes do } \\
\text { spread ex-post. }\end{array}$ \\
\hline $\begin{array}{c}\text { Claessens, } \\
\text { Demirguç-Kunt e } \\
\text { Huizinga (2001) }\end{array}$ & 80 & $1988-1995$ & $\begin{array}{c}\text { Determinantes do } \\
\text { spread ex-post. }\end{array}$ \\
\hline $\begin{array}{c}\text { Maudos e } \\
\text { Guevara (2004) }\end{array}$ & 5 (Europa) & $1993-2000$ & $\begin{array}{c}\text { Determinantes do } \\
\text { spread ex-post. }\end{array}$ \\
\hline $\begin{array}{c}\text { Demirgüç- } \\
\text { Kunt, Laeven e } \\
\text { Levine(2004) }\end{array}$ & 72 & $1995-1999$ & $\begin{array}{c}\text { Evolução e } \\
\text { determinantes do } \\
\text { spread ex-post. }\end{array}$ \\
\hline $\begin{array}{c}\text { Peria e Mody } \\
\text { (2004) }\end{array}$ & 5 (A.L.) & $1995-2001$ & $\begin{array}{c}\text { Evolução e } \\
\text { determinantes do } \\
\text { spread ex-post. }\end{array}$ \\
\hline
\end{tabular}

(continua...) 


\begin{tabular}{|c|c|c|c|}
\hline Estudo & $\begin{array}{c}\text { Número de } \\
\text { Países }\end{array}$ & Período & $\begin{array}{c}\text { Abordagem e } \\
\text { tipo do spread }\end{array}$ \\
\hline Gelos (2006) & $\begin{array}{c}85 \text { (emergentes, } \\
\text { com 14 da A.L.) }\end{array}$ & $\begin{array}{c}\text { Evolução do } \\
\text { spread ex- } \\
\text { ante e ex-post. } \\
\text { Determinantes do } \\
\text { spread ex-post. }\end{array}$ \\
\hline $\begin{array}{c}\text { Schwaiger e } \\
\text { Liebeg (2007) }\end{array}$ & $\begin{array}{c}10 \text { (Europa do } \\
\text { Leste e Central) }\end{array}$ & $2000-2005$ & $\begin{array}{c}\text { Determinantes do } \\
\text { spread ex-ante. }\end{array}$ \\
\hline
\end{tabular}

Quadro 2 - Literatura empírica internacional com análise do spread bancário por grupo de países

Fonte: Elaborado pelos autores com base na literatura citada.

Nota: A.L. significa América Latina.

Demirguç-Kunt e Huizinga (1999) analisam a estrutura e os determinantes do spread bancário ex-post para um conjunto de 80 países, no período 19881995. Os autores utilizam dados de 7900 bancos para calcular, numa primeira etapa, a decomposição do spread ex-post, por meio de sua definição contábil, e para estimar econometricamente, numa segunda etapa, os determinantes do spread ex-post e do lucro antes dos impostos, por meio de regressão em painel. A medida de spread ex-post utilizada é a margem líquida de intermediação (NIM), definida como a razão entre o resultado de intermediação financeira (II) pelo total do ativo (AT), ou seja, a diferença entre as receitas de intermediação (sobre o total do ativo) e as despesas de intermediação (sobre o total do ativo).

A análise descritiva indica que os maiores bancos apresentaram menores margens, lucros e custos administrativos em relação aos menores bancos. Além disso, os resultados econométricos indicam uma série de conclusões em relação às variáveis explicativas, quanto às características dos bancos e dos países, que são detalhadas em seguida. seguinte:

Em primeiro lugar, quanto às características dos bancos, os autores sugerem o

i) bancos mais bem capitalizados (relação capital-ativo) apresentam menor margem e lucro;

ii) bancos estrangeiros, em países em desenvolvimento, apresentam maior margem e lucro do que bancos domésticos, enquanto ocorre o contrário em países desenvolvidos;

iii) maior peso de ativos que não rendem juros (em relação ao ativo total) implica menor margem e lucro;

iv) maior peso de depósitos (soma de depósitos a prazo, depósitos à vista e poupança) em relação ao ativo total é associado a menor lucro; 
v) maior custo administrativo (em relação ao ativo total) resulta em maior margem e menor lucro.

Além disso, quanto às características dos países, os autores sugerem o seguinte:

i) entre as variáveis macroeconômicas, a inflação é associada com maior margem e lucro, enquanto o crescimento econômico não apresenta relação significativa com a margem e com o lucro;

ii) há evidências de que os impostos e requerimentos de reservas sobre os bancos são repassados totalmente aos consumidores, por meio de maior margem e lucro;

iii) a partir de uma regressão específica, controlando as características dos bancos, características macroeconômicas e impostos, há evidências de que a existência de regulação de seguro de depósitos (variável dummy) está associada à menor margem;

iv) a partir de regressão específica para as variáveis da estrutura financeira, controlando as características dos bancos, características macroeconômicas e impostos, há evidências de que os países com setores bancários mais representativos (maior relação ativo do setor sobre o PIB) apresentam menor margem e lucro. Além disso, a concentração (índice de Herfindahl) é positivamente relacionada com maior lucro, e os bancos maiores tendem a apresentar maior margem;

v) a partir de regressão específica para os indicadores institucionais, controlando as características dos bancos, características macroeconômicas e impostos, há evidências de que melhores garantias de contrato, eficiência judicial e menor corrupção estão associadas à menor margem e lucro.

Saunders e Schumacher (2000) analisam a evolução e os determinantes do spread ex-post, medidos pela margem líquida de intermediação, para sete países da Organização para a Cooperação e Desenvolvimento Econômico (OCDE) (Alemanha, Espanha, França, Reino Unido, Itália, Suíça e Estados Unidos) entre 1988 a 1995, com dados de 614 bancos. Nas estimativas econométricas, os autores aplicam o modelo de Ho e Saunders (1981) com regressão de dois estágios. No primeiro estágio, é realizada para cada país uma regressão em cross-section da margem controlando para cada banco dois fatores considerados por Ho e Saunders (1981): os pagamentos implícitos de juros e o custo de oportunidade de reservas, além de um fator não considerado, a relação capital-ativo. Desse primeiro conjunto de regressões deriva um coeficiente linear para cada país em cada período, interpretado como "spread puro". No segundo estágio, é estimada para o conjunto de países uma regressão em painel com o "spread puro" como variável explicada, sendo considerado como fator explicativo o risco de juros (volatilidade da taxa de juros) e interpretando o coeficiente linear resultante como medida da estrutura de mercado. 
A partir das estimativas do primeiro estágio para cada um dos países, Saunders e Schumacher (2000) sugerem que, em geral, os três fatores controlados (pagamento implícito de juros, custo de oportunidade de reservas e relação capital-ativo) apresentam significância estatística e sinal positivo dos coeficientes, conforme esperado. Os resultados do segundo estágio indicam que o risco de juros tem um impacto significativo e positivo no spread puro, confirmando a hipótese do modelo de Ho e Saunders (1981). Ainda, os autores consideram que a medida de estrutura de mercado é significativa, apesar de heterogênea entre os países da amostra (maior na França e Reino Unido e menor nos Estados Unidos). Ademais sugerem que, quanto mais segmentado ou restrito o setor, em relação à abrangência geográfica ou de serviços, maior aparenta ser o poder de mercado, e, em consequência, maior o spread puro.

Concluindo, Saunders e Schumacher (2000, p. 815) recomendam que o foco de política seja na competição e na estabilidade macroeconômica, além de sugerir que a convergência e a estabilidade na área do euro devem resultar em queda na margem, a partir de sua hipótese de que "se uma proporção significativa das margens bancárias num determinado país é determinada pela volatilidade da taxa de juros ao invés do comportamento monopolista dos bancos, então a atenção da política pública deve ter melhor foco nas políticas macroeconômicas, como uma ferramenta para reduzir o custo de intermediação".

Claessens, Demirguç-Kunt e Huizinga (2001) utilizam dados de 7.900 bancos de 80 países entre 1988 e 1995, a mesma base de dados e período de Demirguç-Kunt e Huizinga (1999), mas estendem esse estudo ao examinar como a entrada de bancos estrangeiros, isto é, a mudança na presença de bancos estrangeiros, afeta as margens de intermediação e cada um dos quatro indicadores de sua decomposição contábil: custos administrativos, lucro antes dos impostos, impostos e provisão para inadimplência. $\mathrm{O}$ trabalho apresenta evidências de que nos países em desenvolvimento os bancos estrangeiros apresentam maiores lucros, margens e pagamentos de impostos do que os bancos domésticos, enquanto ocorre o contrário nos países desenvolvidos, corroborando as conclusões de Demirguç-Hunt e Huizinga (1999) em relação aos lucros e margens. São considerados dois fatores de diferenciação que afetam os resultados do banco estrangeiro, ao entrar num país, em relação aos bancos domésticos: as desvantagens informacionais e as vantagens operacionais ou tecnológicas. Os autores associam as maiores margens dos bancos estrangeiros em relação aos bancos domésticos nos países em desenvolvimento à hipótese de que as desvantagens informacionais e ineficiências dos mercados bancários são significativas nesses países e que as vantagens operacionais dos bancos estrangeiros não são capazes de compensar os efeitos dessas desvantagens, implicando maior spread. Nesse contexto, o resultado de maior lucro por parte dos bancos estrangeiros pode ser atribuído ao maior spread cobrado e também à hipótese de vantagens operacionais desses bancos.

Como conclusão, Claessens, Demirguç-Kunt e Huizinga (2001) sugerem que os resultados são consistentes com a hipótese teórica de que no longo 
prazo a entrada dos bancos estrangeiros é capaz de melhorar o funcionamento do mercado bancário, com implicações positivas para os clientes. Para a maioria dos países, uma maior presença de bancos estrangeiros está associada com a redução das margens e dos lucros dos bancos domésticos. Além disso, os autores sugerem que o impacto da entrada do banco estrangeiro na competição local é imediato, e não após o crescimento de sua participação de mercado.

Maudos e Guevara (2004) analisam os determinantes do spread bancário ex-post, medido pela margem líquida de intermediação, para dados de 1.826 bancos de cinco países da Europa (Alemanha, França, Reino Unido, Itália e Espanha) no período 1993-2000. Os autores propõem uma extensão do modelo teórico dos determinantes do spread de Ho e Saunders (1981), com a inclusão do custo operacional e de uma medida direta do grau de competição (índice de Lerner) como variáveis explicativas. Além dessas duas contribuições, os autores consideram como diferenças em relação ao estudo de Saunders e Schumacher (2000): i) a utilização de regressão em um estágio; ii) a delimitação do período mais recente; e iii) o maior número de bancos na amostra, apesar do menor número de países.

Os resultados indicam que a margem de intermediação apresenta relação positiva com o índice de Lerner, custo operacional, aversão ao risco do banco, risco de crédito e risco de juros. Além das variáveis do modelo, apresentaram coeficiente positivo e significativo o pagamento implícito de juros e o custo de oportunidade de reservas e coeficiente negativo significativo a variável qualidade da administração, conforme esperado pelos autores.

Ademais, Maudos e Guevara (2004) sugerem que a queda da margem de intermediação na Europa nesse período é compatível com o aumento do poder de mercado e concentração ocorrido, considerando que esses dois efeitos foram contrapostos pela redução dos custos operacionais, do risco de crédito e do risco de juros. A redução desses três fatores está relacionada a uma conjuntura econômica favorável, de crescimento e estabilidade macroeconômica associada à convergência na área do euro, que resultou na diminuição dos riscos e de aumento do crédito.

Concluindo, Maudos e Guevara (2004) argumentam que a continuidade da redução das margens na Europa estará condicionada à implementação de medidas de incentivo à competição e ao esforço de aumento de eficiência dos bancos, considerando que o ciclo macroeconômico favorável é passível de reversão. Adicionalmente às considerações dos autores, registra-se que sua explicação da redução da margem ocasionada pela diminuição dos riscos corrobora a previsão de Saunders e Schumacher (2000) de que haveria redução do spread devido à maior estabilidade na área do euro no período.

Demirguç-Kunt, Laeven e Levine (2004) examinam os determinantes dos custos de intermediação financeira, utilizando uma amostra com cerca de 1.400 bancos de 72 países entre 1995 e 1999. Especificamente, os autores examinam o impacto da regulação, da estrutura de mercado e do arcabouço institucional no custo de intermediação financeira (medido pelos custos administrativos e pelo spread ex-post), controlando as características específicas dos bancos e dos países. 
Os autores indicam que os resultados para os determinantes da margem de intermediação são similares aos resultados para o custo administrativo, e, em resumo, sugerem o seguinte:

i) as características dos bancos explicam uma parte substantiva dos custos de intermediação financeira, tendo a margem de intermediação e o custo administrativo apresentado relação positiva com a parcela de mercado e negativa com as seguintes variáveis: tamanho, liquidez, patrimônio líquido e receitas de tarifas. A relação com a parcela de mercado é consistente com a hipótese de que os bancos com maior participação de mercado têm capacidade de exercer poder de mercado para ampliar suas receitas;

ii) restrições regulatórias mais significativas, sejam relativas à entrada, à liberdade de negócio ou à operação, implicam, em geral, maiores margens de intermediação e custos administrativos;

iii) todavia, as restrições regulatórias se tornam insignificantes quando são controlados os indicadores institucionais, especialmente o de liberdade econômica e o de proteção aos direitos de propriedade, que apresentam robusta relação negativa com as margens e as despesas administrativas. Por esse motivo, os autores sugerem que a regulação não deve ser observada de forma isolada, pois reflete as características institucionais do país;

iv) quando apenas controladas as características dos bancos, a concentração é positivamente associada com as margens, mas essa relação deixa de ter relevância quando são controladas a inflação e as restrições regulatórias;

v) dentre as variáveis macroeconômicas houve robusta significância apenas para a inflação, que apresenta um impacto positivo na margem operacional e no custo operacional.

Peria e Mody (2004) analisam a evolução e os determinantes do spread ex-post na América Latina no final da década de 1990, com dados de bancos de um conjunto de cinco países: Argentina, Chile, Peru (os três no período 1995-2000), Colômbia (1997 a 2000), México (1998 a 2001). A partir da análise descritiva, os autores observam que a evolução do setor bancário nos países em desenvolvimento tem sido marcada pelo crescimento da participação estrangeira e altos níveis de concentração. Em seguida, examinam o impacto desses dois fatores no spread bancário ex-post por meio de regressão em painel, controlando diversas características dos bancos e dos países.

Segundo esses autores, os resultados obtidos sugerem, em primeiro lugar, que os bancos estrangeiros operam com menor spread ex-post que os bancos domésticos. Esse resultado diverge do encontrado por Claessens, DemirguçKunt e Huizinga (2001), que também utilizam regressão em painel, mas com metodologia diferente (com variáveis em primeira diferença) para um conjunto de países do mundo todo em um período anterior. Entre os bancos estrangeiros, os novos entrantes aparentam operar com níveis inferiores de spread em relação aos níveis dos entrantes por aquisição. Todavia, Peria e 
Mody (2004) levantam dúvidas se são gerados ganhos de bem-estar, pois o menor nível do spread pode ser consequência de uma política de preços mais agressiva ou do fato de que os novos entrantes só emprestam para os segmentos de menor risco, caracterizados por menores spreads bancários. Em segundo lugar, o nível geral de participação estrangeira não aparenta ter impacto direto na redução do spread, mas os autores sugerem que pode haver influência por meio do efeito de redução nos custos administrativos, atribuída à combinação de efeito demonstração e competição potencial. Em terceiro lugar, a concentração bancária apresenta relação positiva importante com o custo administrativo e com o spread, neste caso especialmente para os bancos domésticos. Em quarto lugar, há evidências de que, entre as variáveis de controle por banco, a liquidez e os custos administrativos apresentam relação positiva e significativa com o spread. Em quinto lugar, os autores sugerem que variáveis de controle dos países, ou seja, as características macroeconômicas (inflação, crescimento econômico e taxas de juros de mercado), não apresentam influência direta no spread, mas podem influenciá-lo indiretamente devido ao seu significativo efeito nos custos administrativos.

Concluindo, Peria e Mody (2004) vislumbram extensões do estudo, por meio da ampliação da amostra em relação ao número de países e ao período, e consideram a importância de relacionar os dados bancários com o perfil dos tomadores de empréstimos.

Haber (2004) comenta o estudo de Peria e Mody (2004), considerando que como os custos administrativos são um componente do spread bancário, sua inclusão como variável explicativa na regressão dos determinantes do spread bancário pode gerar subestimação do efeito das outras variáveis. Assim sendo, sugere excluir o custo administrativo dos dois lados da equação, ou seja, que a variável explicada seja o spread líquido do custo administrativo. Sugere também que as variáveis tipo de entrada do banco estrangeiro e país poderiam ser mais bem aproveitadas com metodologia alternativa à inclusão de dummies.

Gelos (2006) examina a evolução do spread ex-ante e ex-post na América Latina e os determinantes do spread ex-post para países emergentes, considerando dados por banco no período 1999-2002 para 85 países em desenvolvimento, entre eles 14 países latino-americanos. A partir de evidências descritivas, o autor observa que os países da América Latina apresentam uma reduzida relação crédito/PIB e altos níveis de spread ex-ante em relação aos padrões mundiais. O spread ex-ante nesses países apresentou relativa estabilidade, em torno de $10 \%$, de 1992 a 2004, mas diminuiu sobremaneira sua dispersão entre os países, especialmente em 1995 e de 2000 a 2002. Gelos (2006) observa também que a média das margens ex-post para os países da América Latina é superior à média de outros países em desenvolvimento.

Gelos (2006) estima regressões em cross-country para o ano de 2002, e sugere que seus resultados indicam que, entre as variáveis de características dos bancos, apenas se mostraram significativas o tamanho do banco, com relação negativa com o spread bancário, e o custo administrativo, com relação positiva. Entre as características dos países, a taxa de juros dos depósitos e os requerimentos de 
reserva apresentaram significativa relação positiva com o spread bancário, enquanto o crescimento econômico apresentou significativa relação negativa,, sendo que esse resultado está associado ao exercício de poder de mercado dos bancos. Todavia, a concentração não apresentou relação significativa com o spread, fato que o autor associa à relação significativa da concentração com o custo administrativo. Além disso, os impostos, o grau de informação e a segurança legal não apresentaram significância estatística na regressão, resultados atribuídos a problemas de mensuração que impedem uma estimação mais precisa desses efeitos.

Gelos (2006) também estima regressões em painel com dados de 1999 a 2002, confirmando as relações das variáveis significativas da regressão anterior, com uma especificidade para os requerimentos de reserva, que apresentaram redução da significância devido ao fato de que não apresentaram variação no tempo. A estimativa também indica significância para os coeficientes positivos de segurança legal e de impostos e para o coeficiente negativo de propriedade estrangeira. Esse último coeficiente corrobora o resultado de Peria e Mody (2004) de que os bancos estrangeiros operam com menores spreads do que os bancos domésticos nos países da América Latina. Todavia, a parcela de bancos estrangeiros no setor não apresentou correlação com o spread, resultado associado à hipótese de que os bancos estrangeiros operam em nichos de mercado caracterizados por maior competição ou menor risco, possibilitando menores spreads.

Concluindo, Gelos (2006) sugere que os países da América Latina apresentam maiores taxas de juros, bancos menos eficientes (maiores custos administrativos) e maiores requerimentos de reservas do que outros países emergentes, e que esses fatores têm um significativo impacto no spread. Todavia, o autor não identifica diferença marcante dos latino-americanos em relação ao restante dos países da amostra quanto aos outros aspectos significativos na determinação do custo da intermediação financeira, como a inflação, os impostos diretos, o tamanho do banco e a relação patrimônio líquido/ativo.

Schwaiger e Liebeg (2007) analisam os determinantes do spread ex-post considerando o processo de transição dos países da Europa do Leste e Central (CEE) na iminência de entrada como membro da União Europeia - dez países da CEE mais a Croácia, no período 2000-2005. Os autores objetivam examinar quais efeitos ambientais ou características do setor bancário em um dado país contribuem para reduzir os custos da intermediação financeira. O fato estilizado é que o spread na região da CEE, com países que tiveram reformas econômicas nos anos 1990, está ainda bem acima dos níveis observados na EU15 , ainda que possua trajetória declinante. É utilizado, para tanto, o modelo de margens líquidas de juros de Ho e Saunders (1981), que considera os bancos agentes avessos ao risco que tomam depósitos e realizam empréstimos, na versão ampliada por Maudos e Guevara (2004). Para avaliar os determinantes do spread, são utilizados dados em painel, com um modelo de efeitos fixos, 
com as seguintes variáveis: margem líquida de juros (receita líquida de juros sobre total de ativos), razão patrimônio líquido sobre total de ativos (aversão ao risco), risco de taxa de juros (desvio padrão da taxa diária no mercado interbancário), risco de crédito (razão empréstimos ao cliente sobre total de ativos), interação entre riscos de crédito e de juros (com uso de um termo de interação entre ambos), custos operacionais (despesas operacionais sobre total de ativos), tamanho médio das operações (log do total de empréstimos aos clientes), estrutura competitiva do mercado (razão de concentração dos cinco maiores bancos). A estrutura de propriedade é vista através da dummy de propriedade estatal ou não estatal, assim como da propriedade estrangeira.

Os resultados obtidos por Schwaiger e Liebeg (2007) mostram que os principais determinantes do spread são: custos operacionais, aversão ao risco, risco de crédito, risco de taxa de juros e grau de concentração, sendo o risco de crédito de longe o mais importante. Assim, menores custos, menor aversão ao risco, menor risco de crédito e risco de taxa de juros, bem como mais competição, são fatores que induzem menores spreads. Quanto às variáveis específicas do banco, a razão custo sobre receita tem efeito negativo e coeficiente significativo, indicando que maior grau de eficiência resulta em maiores margens. $\mathrm{O}$ tamanho do banco não apresentou qualquer influência significativa. A propriedade estrangeira tem impacto significativo (e positivo) sobre o spread (em contraste com a literatura), o que parece evidenciar a existência de um mercado de competição imperfeita, enquanto a propriedade estatal, por sua vez, não tem impacto significativo. O PIB per capita tem efeito negativo significativo sobre spread, mostrando que as margens são mais baixas quanto mais desenvolvida é a economia, da mesma forma que o aumento do aprofundamento financeiro reduz o spread.

\subsection{Uma Avaliação da Literatura}

Os oito estudos de determinantes do spread bancário para painel de países, enumerados no Quadro 2, podem ser considerados para a análise conjunta de resultados em três blocos, de acordo com a amostra de países: i) mundial (CLAESSENS; DEMIRGUÇ-KUNT; HUIZINGA, 2001; DEMIRGÜÇKUNT; HUIZINGA, 1999; DEMIRGÜÇ-KUNT; LAEVEN; LEVINE, 2004); ii) desenvolvidos (MAUDOS; GUEVARA, 2004; SAUNDERS; SCHUMACHER, 2000); e iii) emergentes (GELOS, 2006; PERIA; MODY, 2004; SCHWAIGER; LIEBEG, 2007). Os estudos apresentam diferença em relação aos intervalos de período analisado, entre 1988 e 2005, que constitui limitação a ser considerada, mas não é impeditiva da comparação dos resultados das estimativas empíricas, com relativa concentração na década de 1990.

Observa-se que todos os estudos analisados utilizam dados desagregados por banco e usam a medida do spread ex-post sem tarifas, informação em geral mais facilmente disponível por banco e mais homogênea entre os países. Esses estudos não exploram possibilidades de comparação de diferentes medidas do spread, exceto Gelos (2006) que estima os determinantes para uma segunda 
medida de spread ex-ante, também sem tarifas. Essa parece ser uma possibilidade de contribuição para novos estudos, mas é necessário considerar as limitações da comparação de diferentes medidas entre países, conforme observado para o spread ex-ante por Nakane e Costa (2005), considerando as possibilidades de diferença metodológica de mensuração.

Para as características dos países, observa-se uma importante relação positiva do spread com a volatilidade macroeconômica (conforme previsto por Ho e Saunders, 1981), medida pela volatilidade da taxa de juros nos painéis para países desenvolvidos (MAUDOS; GUEVARA, 2004; SAUNDERS; SCHUMACHER, 2000) e da região do CEE (SCHWAIGER; LIEBEG, 2007), mas também medida por meio da inflação nos painéis mundiais (DEMIRGÜÇKUNT; HUIZINGA, 1999; DEMIRGÜÇ-KUNT; LAEVEN; LEVINE, 2004), sendo que essa última variável não se mostrou significativa para a América Latina (PERIA; MODY, 2004). Para outras variáveis macroeconômicas, há evidências de significância em um painel de países emergentes (GELOS, 2006) com coeficiente negativo para o crescimento econômico e coeficiente positivo para a taxa de juros de mercado, enquanto Peria e Mody (2004) não encontram significância para essas duas variáveis na América Latina. Interessante observar que a relação negativa do spread com o crescimento econômico corrobora a hipótese de ganhos de eficiência dos bancos derivados do aumento do crédito e menor risco de crédito, ao contrário da relação positiva entre spread e crescimento, que indicaria exercício de poder de mercado em conjuntura de maior demanda.

Duas outras características dos países, os impostos e os requerimentos de reserva, apresentam relação positiva com o spread nos painéis do mundo (DEMIRGÜÇ-KUNT; HUIZINGA, 1999) e de emergentes (GELOS, 2006). Além disso, na relação dos índices de concentração com o spread predominaram coeficientes significativos, nesse caso positivos, refletindo exercício de poder de mercado dos bancos nos painéis do mundo (DEMIRGÜÇ-KUNT; HUIZINGA, 1999), de desenvolvidos (MAUDOS; GUEVARA, 2004) e de emergentes (PERIA; MODY, 2004; SCHWAIGER; LIEBEG, 2007). É importante ressaltar também a importância dos indicadores de qualidade institucional dos países, como garantias dos contratos e eficiência judicial, considerados apenas nos painéis mundiais, que apresentaram relação significativa e negativa com o spread (DEMIRGÜÇKUNT; HUIZINGA, 1999; DEMIRGÜÇ-KUNT; LAEVEN; LEVINE, 2004), ou seja, a melhoria institucional tende a gerar redução do spread bancário.

As características dos bancos também apresentaram significância como variáveis explicativas do spread, com destaque para a relação positiva dos custos operacionais, em painéis do mundo (DEMIRGÜÇ-KUNT; HUIZINGA, 1999), de desenvolvidos (MAUDOS; GUEVARA, 2004) e emergentes (PERIA; MODY, 2004; GELOS, 2006; SCHWAIGER; LIEBEG, 2007). Além do custo operacional, dois outros aspectos de custos, o custo de oportunidade de reservas e o pagamento implícito de juros, apresentam significativa relação positiva com o spread para os países desenvolvidos (MAUDOS; GUEVARA, 2004; SAUNDERS; SCHUMACHER, 2000). Interessante observar que a receita de serviços, componente 
do pagamento implícito de juros (medido pela despesa operacional líquida das receitas extra-juros), apresenta relação negativa e significativa com o spread (sem tarifas) em um painel mundial (DEMIRGÜÇ-KUNT; LAEVEN; LEVINE, 2004), o que corrobora os resultados para o pagamento implícito de juros nos países desenvolvidos.

Entre as outras características dos bancos, observa-se que o tamanho do banco (em relação ao ativo) apresenta relação significativa e negativa com o spread em painéis do mundo (DEMIRGÜÇ-KUNT; LAEVEN; LEVINE, 2004) e dos países emergentes (GELOS, 2006), sugerindo importância das economias de escala. Todavia, a parcela de mercado do banco (market share) apresentou relação positiva com o spread no mesmo painel mundial (DEMIRGÜÇ-KUNT; LAEVEN; LEVINE, 2004), resultado que, apesar de não haver demonstração da significância dessa variável nos outros estudos, sugere que os bancos não repassam esse ganho de eficiência aos consumidores, exercendo poder de mercado por meio do estabelecimento de maiores spreads. Nesse sentido, Schwaiger e Liebeg (2007) encontram que nos países da Europa Central e do Leste há uma relação positiva entre grau de concentração e spread bancário.

Há resultados divergentes da relação do spread com o patrimônio líquido (em relação ao ativo) do banco, que é negativa nos painéis mundiais (DEMIRGÜÇ-KUNT; HUIZINGA, 1999; DEMIRGÜÇ-KUNT; LAEVEN; LEVINE, 2004), positiva para os desenvolvidos (MAUDOS; GUEVARA, 2004; SAUNDERS; SCHUMACHER, 2000) e negativa para os emergentes (GELOS, 2006; PERIA; MODY, 2004). Essa variável pode ser interpretada como proxy da aversão ao risco do banco (MAUDOS; GUEVARA, 2004), com expectativa de relação positiva com o spread, confirmada apenas para os países desenvolvidos, sendo que a divergência nos resultados dos outros poderia ser atribuída à sua diversidade institucional ou heterogeneidade entre os bancos.

Além do patrimônio líquido, outra variável significativa, a liquidez, apresenta divergência em sua relação com o spread, sendo negativa em um painel mundial (DEMIRGÜÇ-KUNT; LAEVEN; LEVINE, 2004) e positiva para os países emergentes (PERIA; MODY, 2004). Para os países emergentes foi confirmada a hipótese de que alta liquidez, ocasionada por uma política mais prudencial do banco ou por restrições regulatórias, implica custo de oportunidade para o banco, que tende a repassá-lo para os consumidores por meio de maiores spreads (PERIA; MODY, 2004).

O tipo de propriedade do banco parece influenciar o spread, mas há divergência nas evidências empíricas para os países emergentes. Resultados de painéis mundiais indicam que os bancos estrangeiros apresentam menor spread do que os bancos domésticos nos países desenvolvidos, enquanto nos países emergentes os bancos estrangeiros apresentam maior spread do que os bancos nacionais, esse último resultado associado às desvantagens informacionais encontradas pelos bancos estrangeiros (CLAESSENS; DEMIRGUÇ-KUNT; HUIZINGA, 2001; DEMIRGÜÇ-KUNT; HUIZINGA, 1999). Todavia, há evidências de que os bancos estrangeiros operam com menor spread do que os bancos domésticos em estudos específicos para os países 
emergentes (GELOS, 2006; PERIA; MODY, 2004), resultado que, dadas suas desvantagens informacionais, coloca em questão se os bancos estrangeiros operam com maior eficiência, e política de preços mais agressiva, ou se operam apenas nos segmentos de informação mais transparente ou de menor risco, caracterizados por maior competição e menor spread bancário.

Um insumo para ajudar a responder essa questão é o fato de que não foram encontradas evidências de que o aumento do nível de participação dos bancos estrangeiros tenha relação direta com a redução do spread nos três estudos para os países emergentes (GELOS, 2006; PERIA; MODY, 2004; SCHWAIGER; LIEBEG, 2007), o que afasta a primeira hipótese, de que operam com maior eficiência. Mas esse resultado deve ser visto com cuidado, considerando que Claessens, Demirguç-Kunt e Huizinga (2001) sugerem, para a maioria dos países de um painel mundial, que uma maior presença de bancos estrangeiros está associada com a redução das margens. Essa questão, entre outras relacionadas ao spread bancário, aponta para a importância de considerar, se possível de forma desagregada, a diversidade dos bancos e das operações bancárias na análise do spread bancário.

\section{Considerações Finais}

Este artigo analisa comparativamente as evidências da literatura empírica internacional sobre o spread bancário, com o intuito principal de contribuir para o diagnóstico dos seus determinantes e da sua estrutura, considerando as especificidades dos tipos de medida do spread bancário.

Em primeiro lugar, a avaliação da literatura empírica, com análise individualizada dos países da América do Sul, indicou como principal determinante do spread bancário a volatilidade econômica. As variáveis microeconômicas, por sua vez, apresentaram alguma significância, mas, sobretudo, relevante heterogeneidade entre os países.

Em segundo lugar, a análise dos estudos sobre dados de painéis de países indicou que as características dos países que predominaram como determinantes do spread bancário foram: i) fatores macroeconômicos (volatilidade para painéis mundiais e de desenvolvidos, enquanto para os emergentes houve algum destaque para o crescimento econômico e para a taxa de juros de mercado); ii) concentração de mercado (painéis mundiais, de países desenvolvidos e de países emergentes). Além disso, observou-se destaque nos painéis mundiais para aspectos como a qualidade institucional e o nível de impostos e de requerimentos de reserva (esses últimos dois também relevantes no caso dos painéis de emergentes).

Sobre as especificidades de medida, cabe ressaltar que os estudos sobre os países da América do Sul evidenciam a importância do cuidado na interpretação das estimativas empíricas do spread bancário. Por exemplo, Brock e RojasSuarez (2000) apresentam evidências de significativa heterogeneidade entre os bancos, sugerindo que pode ser enganoso o foco em agregados para entender o comportamento do spread. Além disso, há evidências de diferença nos resultados para as medidas do spread ex-ante e ex-post (BARAJAS; STEINER; 
SALAZAR, 1999; BROCK; FRANKEN, 2003), o que sugere importância para a análise comparativa de diferentes medidas do spread.

Concluindo, sugerimos algumas questões para investigação em trabalhos futuros sobre o assunto no Brasil. Um primeiro aspecto pouco explorado na literatura é a estimativa dos determinantes do spread bancário ex-post, considerando diferentes medidas e comparando os resultados com estimativas similares do spread ex-ante, com a finalidade de investigar se há diferenças nos resultados, conforme sugerido por Brock e Franken (2003). Considerando as evidências de diferenciação entre os segmentos de bancos (COSTA; NAKANE, 2005; GUIMARÃES, 2002) e de modalidades (BANCO CENTRAL DO BRASIL, 1999; PAULA; LEAL, 2006), essas especificidades são um segundo aspecto a ser investigado, com a finalidade de analisar sua contribuição para a explicação do comportamento das medidas agregadas. Esses são alguns caminhos possíveis e interessantes de aprofundamento para outros trabalhos que pretendam analisar o spread bancário no Brasil.

\section{Referências}

AFANASIEFF, T. S.; LHACER, P. M.; NAKANE, M. I. The determinants of bank interest spread in Brazil. Money Affairs, v. 15, n. 2, p. 183-207, 2002.

ANGBAZO, L. Commercial bank net interest margins, default risk, interest-rate risk, and offbalance sheet banking. Journal of Banking and Finance, v. 21, p. 55-87, 1997.

BANCO CENTRAL DO BRASIL. Relatório Juros e Spread Bancário no Brasil. 1999. Disponível em: <http://www.bcb.gov.br/?SPREAD>. Acesso em: 20 ago. 2008.

BARAJAS, A; STEINER, R.; SALAZAR, N. Interest spreads in banking in Colombia, 1974-1996. IMF Staff Papers, v. 46, p. 196-224, 1999.

BROCK, P.; FRANKEN, H. Measuring the determinants of average and marginal bank interest rate spreads in Chile, 1994-2001. Seattle: University of Washington, 2003. Mimeo.

BROCK, P. L.; ROJAS-SUAREZ, L. Understanding the behavior of bank spreads in Latin America. Journal of Development Economics, v. 63, p. 113-134, 2000.

CLAESSENS, S.; DEMIRGUÇ-KUNT, A.; HUIZINGA, H. How does foreign entry affect domestic banking markets? Journal of Banking and Finance, v. 25, p. 891-911, 2001.

COSTA, A.C.; NAKANE, M. Revisiting the methodology for the bank interest spread decomposition in Brazil: An Application of the Theory of Cost Allocation, http://www.ibmecsp.edu.br/pesquisa/ modules/papers.php?topicid=39Etype, 2005.

DEMIRGÜÇ-KUNT, A.; HUIZINGA, H. Determinants of commercial bank interest margins and profitability: some international evidence. World Bank Economic Review, v. 13, p. 379-408, 1999.

DEMIRGÜÇ-KUNT, A.; LAEVEN, L.; LEVINE, R. Regulations, market structure, institutions, and the cost of financial intermediation. Journal of Money, Credit, and Banking, v. 36, n. 3, p. 593-622, 2004. 
DICK, A. Banking spreads in Central America: evolution, structure, and behavior. Cambridge: Harvard Institute for International Development, 1999. (HIID Development Discussion Papers).

GELOS, R. Banking spreads in Latin America. IMF Working Paper 06/44, Feb. 2006.

GUIMARÃES, P. How does foreign entry affect the domestic banking market? The Brazilian case. Latin American Business Review, v. 3, n. 4, p. 121-140, 2002.

HABER, S. Comment on 'How foreign participation and market concentration impact bank spreads: evidence from Latin America. Journal of Money, Credit e Banking, v. 36, n. 3, p. 539-542, 2004.

HO, T.; SAUNDERS, A. The determinants of bank interest margins: theory and empirical evidence. Journal of Financial and Quantitative Analysis,v. 16, n. 4, p. 581-600, 1981.

LEAL, R. M. Estrutura e determinantes do spread bancário no Brasil após 1994: uma análise da literatura empírica. In: PAULA, L. F.; OREIRO, J. L.. (Org.). Sistema Financeiro: uma análise do setor bancário brasileiro. Rio de Janeiro: Campus-Elsevier, 2007. p. 221-251.

MAUDOS, J.; GUEVARA, J. F. Factors explaining the interest margin in the banking sectors of the European Union. Journal of Banking and Finance, v. 28, n. 9, p. 2259-2281, 2004.

NAKANE, M.; COSTA, A. Spread bancário: os problemas da comparação internacional. Risk Update, v. 1, n. 3, p. 9-14, 2005.

PAULA, L. F.; ALVES JR, A. J. Banking behaviour and the Brazilian economy after the Real Plan: a post-Keynesian approach. Banca Nazionale del Lavoro Quarterly Review, n. 227, p. 337-365, 2003.

PAULA, L. F.; LEAL, R. M. Custo do crédito no Brasil: uma avaliação recente. Indicadores Econômicos FEE, v. 34, n. 2, p. 91-102, 2006.

PERIA, S.; MODY, A. How foreign participation and market concentration impact bank spreads: evidence from Latin America. Journal of Money, Credit, and Banking, v. 36, n. 2, p. 511-537, 2004.

SAUNDERS, A.; SCHUMACHER, L. The determinants of bank interest rate margins: an international study. Journal of International Money and Finance, v. 19, p. 813-832, 2000.

SCHWAIGER, M.; LIEBEG, D. Determinants of bank interest margins in Central and Eastern Europe. Financial Stability Report, n.14, p. 68-84, 2007.

SILVA, G. J. C., OREIRO, J. L.; PAULA, L. F. Spread bancário no Brasil: uma avaliação empírica. In: PAULA, L. F.; OREIRO, J. L. (Org.). Sistema Financeiro: uma análise do setor bancário brasileiro. Rio de Janeiro: Campus; Elsevier, 2007. p. 221-251.

SINGH, A. et al. Stabilization and reform in Latin America: A macroeconomic perspective on the experience since the early 1990s. IMF Occasional Paper n. 238, Feb. 2005.

WORLD BANK; IMF. Indicators of financial structure, development, and soundness. In: WORLD BANK; IMF. Financial Sector Assessment: a handbook. Washington: World Bank, 2005. p. 15-33,

Recebido em: 28/10/2009. Aceito em: 23/05/2011. 